\title{
UNSUR UTOPIA DALAM 3 NOVEL KONTEMPORER JEPANG KARYA JIRO AKAGAWA
}

\author{
Nalti Novianti \\ Japanese Department, Faculty of Language and Culture, Bina Nusantara University, \\ Jln. Kemanggisan Ilir III No. 45, Kemanggisan/Palmerah, Jakarta Barat 11480, \\ naltin@binus.edu
}

\begin{abstract}
The concept of Utopia that exist in three Jiro Akagawa's Japanese contemporary novel, described the condition of Japan society nowadays. In the relationship concept that relies on hierarchy and closeness relationship between persona in Japan, Akagawa tried to think out of the box. Akagawa's novel is a mystery novel focusing on society, mostly about the characteristic that influenced by the Uchi and Soto concept. These concepts made Japan society divided into "inner group" and "outer group". Also, this concept made the Japan society not very active in making a relationship outside her/him self. In the style of Akagawa's satire, he described this idea in his novels to convey the message to the reader.
\end{abstract}

Keywords: Utopia, Soto and Uchi concept, satire

\begin{abstract}
ABSTRAK
Konsep Utopia yang ada dalam tiga novel Jepang kontemporer karya Jiro Akagawa sangat menggambarkan keadaan masyrakat Jepang dewasa ini. Dalam konsep pergaulan yang sangat meninggikan masalah hierarki, dan ketatnya pergaulan antar persona di Jepang, Akagawa mengeluarkan semua kreatifitasnya untuk keluar dari kenyataan tersebut. Novel Akagawa merupakan novel misteri yang mengusung masalah kemayarakatan, terutama mengenai sifat ketertutupan masyarakat Jepang yang sangat dipengaruhi oleh konsep Uchi dan Soto. Konsep inilah yang membuat masyarakat Jepang membagi diri menjadi " kelompok dalam" dan " kelompok luar". Konsep ini pula yang membuat mereka dianggap sebagai masyarakat tertutup yang tidak aktif membangun hubungan linear ke luar dirinya sendiri. Dalam gaya satire-nya Akagawa mengemukakan gagasannya dalam novel-novelnya untuk menyampaikan pesan pada pembacanya.
\end{abstract}

Kata kunci: Utopia, Konsep Soto dan Uchi, satire 


\section{PENDAHULUAN}

Karya sastra adalah suatu wadah untuk menyampaikan model kehidupan yang diidealkan dan ditampilkand alam cerita lewat para tokoh. Selain itu juga dapat dijadikan tempat untuk menyampaikan pesan moral yang berhubungan dengan sifat-sifat luhur kemanusian dan memperjuangkan hak-hak dan martabat manusia (Nurgiyantoro, 1998:321). Perkembangan sastra kontemporer di Jepang dimulai sejak jaman Meiji (1686) pada saat kebijakan sakoku, atau penutupan negeri dari masuknya orang asing telah yang berlaku selama hampir 400 tahun lamanya akhirnya dihapuskan. Perkembangan sastra kontemporer sendiri tidak lepas dari peranan pengaruh barat yang telah mengalami asimilasi dan atau akulturasi dengan budaya Jepang.

Penulisan karya sastra yang merupakan cerminan fenomena di masyarakat, tidak lepas dari unsur-unsur budaya itu sendiri. Dalam novel kontemporer karya Jiro Akagawa, penulis menemukan gambaran jelas tentang tata laku yang berdasar pada tata budaya masyarakat Jepang. Unsur budaya yang tercermin di dalamnya adalah adanya konsep Uchi dan Soto dalam pergaulan keseharian masyarakat Jepang.

Dalam penelitian kali ini penulis akan menelitian masalah unsur utopia dalam 3 novel karya Jiro Akagawa yang bergenre fantasi, dihubungankan dengan konsep masyarakat Jepang yaitu Uchisoto, terutama masalah ninjo.Teori yang penulis gunakan untuk menganalisis tiga novel karya Jiro Akutagawa adalah, konsep Utopia, dan konsep pemikiran uchi-soto dalam hal ini dititikberatkan pada ninjoo dalam masyarakat Jepang.

\section{Konsep Utopia}

Sir Thomas More adalah yang pertama kali membahas masalah utopia pada tahun 1516. Fortunanti dalam Moichi dalam Purnama Sari (2008) menyatakan bahwa karakteristik utama utopia terletak pada pergeseran posisi antara dunia yang diharapkan dan realita yang ada. Dalam hal ini realiti berlawanan dengan dunia yang diharapkan karena, utopia adalah permainan antara dua kutub yakni realitas dan fiksi.

Utopia yang akan penulis munculkan dalam penelitian kali ini adalah utopia yang berhubungan dengan cerita fantasi. Hal ini karena utopia sendiri sangat menitikberatkan pada kontrasnya ideaisme utopis (penggagas utopia) dengan realitas yang tidak sempurna menurutnya. Demi pelariannya terhadap realita, utopia Jepang umumnya memiliki logika terbalik dan tak jarang memutarbalikkan realitas. Kisah fantastik Jepang tidak hanya kembali pada mitos-mitos lokal yang sudah ada melainkan dengan juga membentuk dunia sendiri yang lebih " modern " dan di saat yang sama juga menggambarkan situasi sebenarnya yang ada di Jepang. Karya utopia menjadi identik dengan karya sastra bergaya satire yang berisi kesedihan yang mendalam, kritik, celaan, sekaligus harapan dan kepercayaan akan berbagai macam kemungkinan yang terjadi di masyarakat (Napier dalam Purnama Sari, 2008)

Dapat disimpulkan bahwa utopia adalah konsep ide dunia imajinatif yang muncul akibat suatu kondisi yang dianggap tidak memuaskan oleh utopis. Mereka menciptakan satu dunia imajiner yang baru untuk mencurahkan harapan dan kritik yang tidak bisa disampaikan di dunia nyata.

Unsur utopia dalam 3 novel karya Jiro Akagawa yang menjadi korpus data dalam penelitian ini adalah mengangkat masalah fantasi ke dalam dunia nyata. Adanya mahluk-mahluk yang serupa dengan manusia, dan bertingkah layaknya manusia merupakan satu gambaran ide dari sang pengarang dalam menciptakan satu dunia baru yang lain dari realitas yang ada. 
Akan tetapi unsur ke-Jepangan tetap ditampilkan, untuk menunjukkan bahwa pelarian dari dunia nyata ke dunia utopia yang diidealkan oleh utopis terjadi di Jepang. Dalam hal ini pengarang menitikberatkan pada unsur uchi-soto yaitu ninjo, sebagai alat penggagas menuju dunia utopia yang ingin diciptakannya.

\section{Konsep Uchi-Soto}

Konsep pemikiran mengenai uchi dan soto dalam masyarakat Jepang menurut Ono (1978:73) adalah merupakan sebuah konsep pemikiran yang mengelompokkan manusia berdasarkan hubungan akrab dan jauh. Orang yang berada di dalam lingkaran dalam (termasuk diri sendiri, atau kelompok dimana diri kita termasuk anggotanya) disebut uchi, dan kelompok orang yang berada di luar lingkaran uchi disebut soto. Kedua konsep ini tercermin dalam perilaku orang Jepang dalam berbahasa. Mereka menggunakan bentukan bahasa sopan untuk bicara dengan orang di luar kelompoknya (lihat Tabel 1), dan menggunakan bentukan bahasa biasa dalam percakapan dengan orang dalam lingkar Uchi.

Tabel 1 Bentuk bahasa sopan dalam bahasa Jepang

\begin{tabular}{lll}
\hline Kata & Bentuk biasa & Bentuk sopan \\
\hline & & Meninggikan/ Merendahkan \\
Makan & Tabemasu & Meshiagarimasu / Itadakimasu \\
\hline
\end{tabular}

Dalam kelompok Uchi, dikenal sebuah perlakuan yang disebut ninjo yang dapat disamakan dengan istilah Omoiyari, atau rasa pengertian yang mendalam di dalam kelompok terbatas. Ninjo sangat mengedepankan 'kyookan' yang berarti perasaan simpati atau kehangatan yang dicurahkan oleh para anggota kelompok uchi untuk sesama anggotanya. Dalam istilah 'kyookan' tersebut terdapat unsur 'shinsetsusa' yang berarti kebaikan atau keramahan yang dilakukan oleh para anggota kelompok. Hal seperti ini tidak dilakukan untuk orang yang ada di luar lingkaran uchi atau yang disebut kelompok soto (Makino, 1996: 23-24).

Dalam penggunaan bahasa maupun dalam kehidupan sehari-hari, untuk kelompok soto orang Jepang lebih sering menggunakan bahasa sopan, yang menandakan bahwa mereka adalah orang luar dan bukan termasuk dalam kelompok uchi. Hal ini juga dilakukan bila bicara dengan orang yang lebih tua, karena masalah hierarki 'jyogekankei' yang sangat berpengaruh dalam pergaulan sehari-hari (Hirabayashi \& Hama, 1992: 3).

\section{Unsur Utopia dalam Tiga Novel Jepang Kontemporer Karya Jiro Akagawa dalam Hubungannya dengan Konsep Uchi dan Soto di Masyarakat Jepang}

Penulis menganalisis tiga novel karya jiro Akagawa, untuk mencari unsur Utopia yang dihubungkan dengan konsep uchi-soto masyarakat Jepang. Adapun judul novelnya adalah 'Odayakana rinjin' (tetangga yang menyenangkan) ", 'Shi ga futari wo wakatsu made '( Sampai mati memisahkan keduanya) ", dan 'Gogo reiji no wasuremono' (Barang yang tertinggal pada jam 12 malam) ”. Ketiga novel ini bergenre fantasi misteri.

Jiro Akagawa sendiri adalah seorang pengarang novel kontemporer misteri yang lahir tahun 1948 di perfektur Fukuoka. Debutnya dimulai ketika dia mendapatkan penghargaan sebagai penulis muda terbaik tahun 1976, melalui karya serinya yang berjudul "Yuurei Ressha ". Setelah itu karyakaryanya sering mencetak predikat best seller. Bahkan, beberapa telah diangkat menjadi cerita sinetron misteri remaja yang banyak digemari, seperti seri 'Sanshimai tantei' atau "tiga detektif bersaudara". Karya-karyanya ada juga yang mengalami perubahan bentuk dan diproduksi menjadi materi game Nintendo DS bergenre misteri berjudul ’ Tsuki no Hikari ', atau cahaya sang bulan. 
Karya-karyanya yang beralur sederhana meski penuh dengan teka-teki, mudah dimengerti oleh setiap generasi pembaca. Selain itu penggunaan bahasa dan kanji atau huruf Jepang dengan tulisan struk sederhana membuat kalimat-kalimatnya mudah untuk dipahami. Hingga tahun 2008 sudah 500 buku yang telah ditulis dan dirilis di masyarakat. Jiro Akagawa selalu menuliskan karya-karyanya sebelum angkat cetak dengan tangan, padahal penulis lain telah beralih menggunakan komputer. Akagawa mengatakan bahwa menulis dengan tangan membuat buah pikiranya lebih mudah untuk disalurkan.

\section{HASIL DAN PEMBAHASAN}

\section{Unsur Utopia yang Berhubungan dengan Konsep Uchi-Soto di Masyarakat Jepang dalam Novel 'Odayakana Rinjin' (tetangga yang menyenangkan), Karya Jiro Akagawa}

Novel ini berkisah mengenai keluarga muda Noburo Ogawa, istrinya Yuko dan anaknya Rie mendapatkan tetangga baru yaitu keluarga Yasuo Ozawa, istrinya Yumi dan anaknya Kumiko. Saat itu mereka sudah setahun menempati rumahnya di sebuah komplek perumahan di pinggiran kota, yang masih sepi dan jarang penghuninya. Karena kemiripan dari segi usia, hobi dan lain-lain, maka mulamula keluarga mereka bersahabat erat. Noburo dekat dengan Yasuo, sementara Yuko merasa sedang berbelanja ke kota ditemani Yumi, dan anak mereka tampak sangat akrab dengan Kumiko Ozawa. Sampai akhirnya terjadi keanehan-keanehan yang membuat Yuko curiga, apalagi setelah dia melihat ada perempuan muda yang wajahnya sangat mirip dengan Yumi ditemukan terbunuh di pusat pertokoan, saat dia sedang berbelanja bersama temannya tersebut.

Berdasarkan informasi dari seseorang bernama Matsubara, Yuko akhirnya mengetahui bahwa ketiga orang yang tinggal di sebelah rumahnya itu adalah mahluk halus yang sedang mencari jasad untuk dapat hidup kembali di dunia ini. Keluarga mereka menjadi target karena usia mereka yang sama. Mahluk halus itu bisa hidup apabila seluruh keluarga Ogawa disingkirkan dari dunia ini. Gambaran jelas mengenai utopia dalam novel ini tampak pada satu realita sebuah keluarga muda yang menempati rumah baru yang jauh dari kota. Di Jepang fenomena seperti ini sudah biasa terjadi, hal ini karena harga rumah di dalam kota tidak terjangkau oleh karyawan dengan gajih yang masih rendah. Keluarga Ozawa tinggal di sebuah kompleks yang baru dibangun, letaknya jauh dari statsiun, tidak ada super market, tidak ada mesin penjual otomatis, dan bahkan kadang kompleks perumahan mereka dtutupi oleh kabut (Akagawa, 2006).

Hal ini diaminkan oleh Kouji Kimura seorang manajer perusahaan otomatif kepada koran Pikiran Rakya. Kimura mencontohkan, harga apartemen berukuran kecil (tiga kamar) di wilayah Osaka (kota terbesar kedua di Jepang setelah Tokyo) bisa mencapai 50 juta yen (Rp 4 miliar). Oleh karena itu, dia rela tinggal di kota kecil Nara dengan membangun rumah sendiri seharga 21 juta yen (Rp 1,68 miliar). "Harga ini tidak termasuk tanahnya seluas $200 \mathrm{~m} 2$ milik orang tua saya. Meski gaji saya lumayan besar, tetapi saya memilih tinggal di daerah Nara, sekitar $45 \mathrm{~km}$ dari Osaka karena harga tanah dan rumah di Osaka sangat mahal," (Asmowiyoto, 2007).

Tingginya kepadatan penduduk dan juga disebabkan tingginya biaya hidup tersebut, maka sebagian besar suami-istri di negara itu hanya memiliki satu atau dua orang anak. Mereka umumnya tinggal di rumah atau apartemen dengan dua atau tiga kamar. Kebanyakan para suami bekerja dan para istri berada di rumah mengurus anak dan rumah tangga. Sebagai karyawan, umumnya para kepala rumah tangga itu berangkat dan pulang kerja di kota naik kereta api. Mereka berangkat pagi dan pulang malam hari termasuk menggunakan kereta api bawah tanah (subway) yang biasanya dijubeli penumpang. Mereka itulah masyarakat kelas menengah Jepang dewasa ini yang seringkali dilanda stres akibat beratnya beban kehidupan (Asmowiyoto. 2007). 
Jadi dunia imajiner utopia karya Akagawa ini digambarkan tidak jauh berbeda dalam dengan keadaan Jepang secara umum. Hal ini sesuai dengan teori Napier (dalam Purnama Sari, 2008) yang mengatakan bahwa, demi pelariannya terhadap realita, utopia Jepang umumnya memiliki logika terbalik dan tak jarang memutarbalikkan realitas. Kisah fantastik Jepang tidak hanya kembali pada mitos-mitos lokal yang sudah ada melainkan dengan juga membentuk dunia sendiri yang lebih "modern" dan di saat yang sama juga menggambarkan situasi sebenarnya yang ada di Jepang. Hal ini sesuai dengan karakteristik utopia yakni permainan antara realita dan dan fiksi, dimana utopia terletak pada keambiguitasan keduanya.

Wujud fantastik dan imajiner dalam novel ini digambarkan saat keluarga Ozawa bertetangga dengan keluarga Miyazawa, mahluk halus yang sedang mencari sebuah keluarga yang umurnya sama, pekerjaannya sama dan punya hobi yang sama, agar mereka dapat merebut jasadnya, dan hidup terus untuk meneruskan hidup korbannya tersebut (Akagawa, 2006: 258-270).

Mula-mula Yumi Miyazawa membunuh suami Yuko, Noboru Ozawa, dan merebut pakaian pria itu untuk dipakaikan pada suaminya. Dengan menggunakan barang-barang kepunyaan korban, maka mereka akan bisa merebut hidup sang korban. Syaratnya adalah tidak boleh ada satupun barang yang lupa mereka rebut. Apabila ada, dan barang itu sudah tersentuh orang lain sebelum mereka mengambilnya, maka mahluk halus itu akan langsung berubah menjadi debu (Akagawa, 2006: 268269). Dan itulah yang dilakukan Matsubara, pria yang kerabatnya pernah terkena masalah yang serupa. Matsubara inilah yang akhirnya menolong Yuko terbebas dari keluarga Miyazawa, yang kembali menjadi debu (Akagawa, 2006: 266-267).

Dalam rahim Yuko ternyata sedang berkembang janij, namun yang perempuan itu tidak ketahui adalah bahwa ayah dari anak itu adalah Yasuo Miyazawa, yang datang ke kamarnya malam tahun baru, sebagai suaminnya. Sementara suaminya sendiri Noboru Ozawa sedang berada di kamar tetangganya Yumi Miyazawa (Akagawa, 2006: 274-275). Hal ini juga merupakan sebuah fantasi imajiner seorang utopias yang menyamakan mahluk halus dengan manusia yang bisa berkembang biak. Akagawa menggambarkan sosok mahluk halus sesuai dengan manusia yang bisa bernapas, bertumbuh, menerima rangsangan dan lain-lain. Akagawa juga tampaknya memunculkan unsur satire pada tokoh Yuko, yang tidak dapat membedakan perlakuan suaminya dan bukan saat mereka sedang menghabiskan waktu berdua. Hal ini menggambarkan fenomena keluarga Jepang yang karena kesibukan para suami, jarang menghabiskan waktu dengan keluarganya. Orang Jepang sanggup berkorban dengan bekerja lembur tanpa mengharap bayaran. Mereka merasa lebih dihargai jika diberikan tugas pekerjaan yang berat dan menantang. Bagi mereka, jika hasil produksi meningkat dan perusahaan mendapat keuntungan besar, secara otomatis mereka akan mendapatkan balasan yang setimpal. Dalam pikiran dan jiwa mereka, hanya ada keinginan untuk melakukan pekerjaan sebaik mungkin dan mencurahkan seluruh komitmen pada pekerjaan (Wan Seng: 2007).

Unsur satire dalam karya Akagawa ini terlihat pada tokoh Noboru Ozawa, yang diletakkan pada posisi seorang suami yang tidak setia terhadap istrinya. Gejala fenomena hedonis yang muncul di kota-kota besar diangkat oleh pengarang sebagai salah satu hal yang ditonjolkan pada karya ini.

Adapun unsur uchi dan soto, ninjoo yang terdapat dalam novel odayakana rinjin dapat dilihat pada Tabel 2 di bawah ini. 
Tabel 2 Utopia dalam おだやかな隣人 ‘odayakana rinjin’

yang berhubungan dengan unsur konsep " uchi " dan "soto“ ninjo

dalam masyarakat Jepang

\begin{tabular}{ll}
\hline Halaman bagian cerita & Utopia yang mengandung unsur Uchi-soto “Ninjoo” \\
\hline 91-95, 146-152, 164-166, 181-182 & Noburo Ozawa serasa mendapatkan teman yang sehati, bertemu dengan \\
Yasuo Miyazawa. Mereka sama-sama karyawan kantor yang punya hobi & yang sama. Dalam waktu sebulan Noburo Ozawa telah menerima Yasuo \\
Miyazawa dalam lingkup uchi-nya & Noboru Ozawa menerima ajakan Yasuo Miyazawa untuk \\
1. & menghabiskan malam bersama istri temannya tersebut karena ingin \\
& menolong mengembalikan keharmonisan hubungan suami-istri \\
& keluarga Miyazawa. \\
2. & Noburo Ozawa tidur dengan istri tetangganya tersebut, dan bahkan \\
& mengulanginya lagi di sebuah hotel atas akan istri Yasuo \\
& Miyazawa, Yumi.
\end{tabular}

26-29, 76-77, 246-248

20-27, 66-71, 142-145,
Eri Ozawa yang selama ini merasa kesepian selalu memenuhi apa yang dikatakan Kumiko Miyazawa. Hal ini terjadi karena Eri merasa berhutang budi pada Kumiko yang mau menemaninya bermain sepanjang waktu. Permintaan Kumiko yang dituruti Eri adalah:

1. Merahasiakan lubang yang mereka gali pada orang tuanya.

2. Mengikuti semua gaya Kumiko, karena Eri menganggap Kumiko tahu segalanya

3. Eri merasa tidak boleh mengikuti ajakan Kumiko ke hutan malam itu, namun dia menurut juga, hingga akhirnya didorong Kumiko masuk ke dalam lubang, agar dia bisa menjadi Eri yang baru.

Yuko Ozawa berusaha untuk menjadi seorang tetangga yang baik bagi keluarga Miyazawa karena merasa berhutang budi pada keluarga Miyazawa. tersebut. Kompleks perumahan tempat mereka tinggal masih sangat sedikit penghuninya, keluarga Miyazawa adalah teman baik mereka. Yuko merasa dia harus menjaga perasaan keluarga tetangganya itu. Dan dia menerima Yumi Miyazawa sebagai anggota lingkup uchi-nya

1. Meskipun Yumi Miyazawa selalu mengikuti gaya fashion dia, Yuko merasa tidak terganggu karena telah menganggap Yumi sebagai anggota $u$ chi.

2. Walaupun merasa terganggu karena keluarga tetangganya sudah mulai sering berkunjung ke rumah dalam waktu yang jelas, tapi Yuko merasa wajar karena merasa satu keluarga.

3. Yuko dan Yumi sudah menggunakan bahasa biasa dan bukan menggunakan bahasa sopan layaknya dua tetangga yang hubungannya jauh.

(Akagawa, 2006)

Ninjoo, seperti yang telah digambarkan pada beberapa adegan di atas menggambarkan keluarga Jepang yang hubungannya begitu akrab, sehingga dalam setiap perlakuan terhdapa anggotanya melakukan apa yang disebut dengan shinsetsusa dan omoiyari. Kata omoiyari menurut kamus gakushuu kokugojiten (Kaneda, 1993:134) berarti 人を考えてやる気持ち、同情 'hito wo kangaete yaru kimochi', 'doujyou', perasaan untuk melakukan sesuatu bagi orang lain, atau merasa punya perasaan yang sama dengan orang lain.

Tokoh Noboru Ozawa sesuai dengan sikap sebagai seorang tetangga baru di dunia nyata, selalu berusaha untuk bersikap baik pada tetanganya. Apalagi Yoshio Miyazawa begitu baik padanya, padahal mereka baru satu bulan yang lalu pindah ke kompleks rumah mereka. Hal ini sesuai dengan teori ninjoo, yaitu atau rasa pengertian yang mendalam di dalam kelompok terbatas. Ninjoo sangat mengedepankan 'kyookan' yang berarti perasaan simpati atau kehangatan yang dicurahkan oleh para anggota kelompok uchi untuk sesama anggotanya (Makino, 1996: 23-24). Dalam hal ini wajar apabila 
Noboru Ozawa sudah menganggap Yasuo Miyazawa sebagai bagian dari lingkar uchi nya karena keduanya sering bertukar kebaikan masing-masing. Akan tetapi unsur utopia kemudian dimunculkan oleh pengarang, dengan memunculkan usulan Yasuo Miyazawa kepada Noboru Ozawa untuk menemani istrinya di malam tahun baru yang akan datang.

Sedangkan pada tokoh Eri Ozawa, Akagawa memberikan realita bahwa banyak keluarga Jepang yang mempunyai anak tidak dalam jumlah banyak. Hal ini karena biaya untuk membersarkan anak tidak murah. Hal ini dapat dilihat pada sebuah artikel di koran pikiran rakyat, "Tingginya kepadatan penduduk dan juga disebabkan tingginya biaya hidup tersebut, maka sebagian besar suamiistri di negara itu hanya memiliki satu atau dua orang anak. Mereka umumnya tinggal di rumah atau apartemen dengan dua atau tiga kamar. Kebanyakan para suami bekerja dan para istri berada di rumah mengurus anak dan rumah tangga "(Asmowiyoto, 2007). Hal ini mengakibatkan anak-anak tidak mempunyai banyak saudara dalam keluarga. Kompleks baru yang ditempati keluarga Ozawa adalah sebuah kompleks perumahan yang baru saja dibuka, dan belum banyak penghuninya. Eri Ozawa kesepian dan merasa butuh teman. Karena itulah, ketika Kumiko Miyazawa datang menjadi tetangga barunya, Eri berusaha jadi teman Kumiko yang baik. Dalam hal ini Eri yang telah menganggap Kumiko sebagai teman dekatnya, yang berarti sudah masuk ke dalam kelompok uchi-nya. Dan dia memberikan ninjo nya pada Kumiko, sebagai bentuk dari omoiyari, demi pelariannya terhadap realita. Hal tersebut sesuai dengan teori Napier (1996:14 dalam Purnama Sari) yang menyatakan bahwa utopia Jepang umumnya memiliki logika terbalik dan tak jarang memutarbalikkan realitas. Kisah fantastik Jepang tidak hanya kembali pada mitos-mitos lokal yang sudah ada melainkan dengan juga membentuk dunia sendiri yang lebih "modern" dan di saat yang sama juga menggambarkan situasi sebenarnya ada.

Tokoh Yuko digambarkan sebagai istri yang baik, dan dia merasa amat senang mendapatkan teman baru (Akagawa, 2006: 80-85). Karena itu biarpun dia merasa sedikit heran atas kelakukan Yumi yang membeli tas sama persis dengan kepunyaan dia, menggunakan dapur keluarga Ozawa, dan selalu ada di saat yang tidak layak untuk bertamu, dia tetap menganggap Yumi ada dalam lingkar uchi nya. Bahasa yang digunakanpun bukan lagi bahasa sopan layaknya orang yang hubungannya jauh, tapi mereka sudah menggunakan bahasa untuk sehari-hari. Menurut Hirabayashi dan Hama (1992: 3), untuk membicarakan subjek orang dari kelompok luar 'soto', orang Jepang menggunakan bahasa hormat atau yang meninggikan 'sonkeigo', namun untuk membicarakan orang dalam 'uchi', mereka menggunakan 'kenjoogo', atau untuk bahasa merendahkan diri.

\section{Unsur Utopia yang Berhubungan dengan Konsep Uchi-Soto di Masyarakat Jepang dalam Novel 'shi ga futari wo wakatsu made' (sampai maut memisahkan keduanya) karya Jiro Akagawa}

Yurie Yonehara mempunyai kondisi jantung yang buruk sejak masih sekolah. Karena itu hidupnya tidak pernah lepas dari pengawasan dokter. Suatu hari dia merasakan detak jantungnya betul-betul berhenti, saat dia kaget ketika menjatuhkan sebuah gelas yang sedang dicucinya. Akan tetapi, walaupun demikian dia merasa masih hidup. Ketika dia keluar apartemen dan terpaksa bersentuhan tangan dengan tetanganya, dia merasa tenaganya bertambah dan semakin hidup, sedangkan tetangganya sendiri langsung meninggal sesaat setelah meninggalkannya. Yurie akhirnnya menyadari bahwa dia bisa terus "hidup“ dengan menghisap jiwa orang-orang yang ada disekitarnya. Dia kemudian meninggalkan apartemennya, untuk lari dari orang-orang yang dicintainya, agar dia tidak menyentuh mereka.

Dokter Kazami ahli jantung yang selama ini menangani pengobatannya Yurie adalah sahabat suaminya Koozoo. Pada hari jantung Yurie berdetak, dia memanggil suaminya untuk menceritakan bahwa ketika dia memeriksa Yurie minggu lalu, dia merasa ada sesuatu yang ditarik dan mengalir masuk ke tubuh Yurie. Dan, setelah dia memeriksa dengan menyentuh Yurie, rambutnya langsung 
menjadi putih. Yurie yang sedang berusaha untuk bertahan hidup diluar sana, berusaha mempergunakan kecantikan sebagai pemikat untuk laki-laki agar mau masuk hotel dengannya. Akan tetapi Yurie hanya menjadikan mereka sebagai objek yang dapat memperpanjang umurnya saja. Wanita itu menyentuhkan tangannya pada mereka, sementara sedikitpun dia tidak berkhianat pada suaminya. Istri Dr Kazami bertekad untuk menangkap Yurie hidup-hidup agar dapat dijadikan sebagai objek penelitian bagi suaminya. Dia mengajak seorang mahasiswa bernama Ryousuke Uchiyama, untuk membantunya. Mereka akhirnya bisa menangkap Yurie dan memasukkannya ke dalam gudang bawah tanah di vila terpencil milik keluarga Kazami. Akan tetapi berkat bantuan Mizusawa, seorang lelaki yang mencintai Akiyo, seorang mahasiswa sahabat Ryousuke menolongnya keluar dari gudang tersebut.

Karena Mizusawa telah menolongnya Yurie mengatakan pada lelaki itu untuk tidak menyentuhnya kalau tidak mau mati. Mereka bersembunyi di sebuah hotel, namun akhrinya ketahuan. Koozoo suaminya kemudian mengejar Yurie yang lari setelah ditembak oleh Michiko Kazami, yang geram karena sebelum Yurie kabur dari vilanya, perempuan itu telah mengambil sebagian nyawa suaminya. Kondisi Yurie mulai melemah Koozoo kemudian membopong istrinya, yang membuat rambutnya jadi putih semua. Lelaki itu kemudian meminta kepada Akiyo untuk membantunya menyetir mobil hingga tebing, dan menyuruh untuk meluncurkan mobil itu langsung ke jurang.

Unsur utopia dalam novel ini digambar dengan munculnya seorang wanita yang bisa memperpanjang umurnya dengan menghisap nyawa orang lain. Satu hal yang tidak ada di dunia realita, namun Akagawa menyelipkannya dalam dunia nyata. Yurie Yonehara, sebetulnya seorang ibu rumah tangga biasa, yang hidup normal dengan suaminya. Realita yang digambarkan Akagawa di sini jelas mengambil seting sebuah kehidupan suami istri di Jepang, yang jarang bersentuhan antara satu sama lain karena kesibukan suaminya (Akagawa, 2010: 61-65). Hal ini diungkapkan oleh ahli kemasyarakatan Wan Seng (2007). Sangat mahalnya harga barang dan biaya hidup di Jepang, salah satu penelitian seperti diungkapkan Ann Wan Seng (2007) yang menjelaskan, perbandingan biaya hidup di Tokyo hampir satu setengah kali lipat biaya hidup di New York, Paris, dan Berlin. Biaya hidup yang terlalu tinggi itu menjadi kenyataan yang harus dihadapi bangsa Jepang, meski sebelumnya juga sempat mengundang protes dari banyak warga Jepang khususnya masyarakat yang berpenghasilan rendah. "Namun, mereka sudah terbiasa dan dapat menyesuaikan diri dengan keadaan tersebut. Cara yang mereka lakukan adalah bekerja lebih keras daripada bangsa lain," tulis Ann Wan Seng (Asmowiyoto, 2007). Dan hal inilah yang menyelamatkan jiwanya. Karena dia belum menyentuh istrinya, maka nyawanya tidak tersedot dan berpindah ke tubuh istrinya.

Sementara Kazami dokter yang merawat Yurie Yonehara, mempunyai keinginan besar untuk mengetahui penyebab mengapa ada manusia yang seperti wanita itu. Dia dengan dibantu istrinya serta dua mahasiswa akhirnya dapat menangkap Yurie dan bermaksud untuk menjadikannya sebagai objek penelitian. Akan tetapi nyawanya sendiri malah terhisap oleh Yurie, dan menyebabkan dia koma. Pada akhirnya justru dia sendiri yang menjadi mayat hidup dan hanya bisa memperpanjang usianya dengan menyedot nyawa orang lain (Akagawa, 2010: 324-326). Satu unsur utopia lagi dimunculkan di sini, bahwa sifat para mayat hidup ini mirip dengan cerita drakula, yang menyebarkan virus pada orang yang dilukainya, dan menjadikan mereka seperti dirinya. Garis imajiner dari dunia nyata terlihat ditarik dengan jelas di sini. Hal ini sesuai dengan teori yang menyatakan bahwa, kisah fantastik Jepang tidak hanya kembali pada mitos-mitos lokal yang sudah ada melainkan dengan juga membentuk dunia sendiri yang lebih "modern" dan di saat yang sama juga menggambarkan situasi sebenarnya yang ada di Jepang (Napier dalam Purnama Sari, 2008).

Unsur Satire diperlihatkan pada tokoh Michiko Kazami, seorang istri yang begitu antusias membantu suaminya dalam meraih kejayaan. Hal ini justru berujung pada kemalangan yang menimpa suaminya. Dalam novel ini unsur utopia dalam hubungannya dengan unsur uchi-soto 'ninjoo ' banyak terdapat dalam kehidupan suami - istri keluarga Yonehara yaitu Yurie dan Koozoo. Adapun kandungan unsur tersebut dapat dilihat pada Tabel 3 di bawah ini. 
Tabel 3 Utopia dalam 死が二人を分かつまで ' shi ga futari wo wakatsu made’ yang mengandung unsur “uchi” dan”soto”, ninjo dalam masyarakat Jepang

\begin{tabular}{|c|c|}
\hline Halaman bagian cerita & Utopia yang mengandung unsur Uchi-soto 'Ninjooka' \\
\hline Yurie & $\begin{array}{l}\text { Yurie melarikan diri dari rumah setelah mengetahui yang } \\
\text { terjadi pada dirinya, agar suaminya tidak menyentuhnya, dan } \\
\text { kemudian mati. }\end{array}$ \\
\hline $132-135$ & $\begin{array}{l}\text { Yurie pulang ke rumah pada saat suaminya diprediksi tidak } \\
\text { ada di rumah untuk mengambil barang-barangnya agar dia } \\
\text { tidak usah bertemu dengan suaminya }\end{array}$ \\
\hline $140-142$ & $\begin{array}{l}\text { Yurie tahu bahwa suaminya sangat mencintainya, oleh karena } \\
\text { itu biarpun dia memanfaatkan kecantikannya untuk } \\
\text { mendapatkan laki-laki calon korbannya, tapi dia tidak pernah } \\
\text { tidur dengan satupun para lelaki itu. }\end{array}$ \\
\hline $\begin{array}{l}\text { Koozoo } \\
\quad 36-61,113-118, \\
131-139,228-230,\end{array}$ & $\begin{array}{l}\text { Koozoo tidak ingin istrinya menjadi pembunuh, karena itu dia } \\
\text { berusaha dengan keras untuk mencari istrinya, dan } \\
\text { menghentikan perbuatannya. Koozoo tahu itu berarti istrinya } \\
\text { harus mati. }\end{array}$ \\
\hline $306-313$ & $\begin{array}{l}\text { Koozoo Yonehara, memangku istrinya ke mobil, dia } \\
\text { menyuruh Akiyo untuk menyetir mobilnya hingga tebing dan } \\
\text { menerjunkannya ke dasar jurang, agar dia bisa mati menemani } \\
\text { istrinya. }\end{array}$ \\
\hline
\end{tabular}

(Akagawa: 2010)

Dalam cerita ini tidak dikisahkan bagaimana Yurie tahu bahwa dengan menyentuh orang lain, maka nyawa orang itu akan berpindah kepadanya. Satu hal yang pasti dia merasa khawatir kalau tetap berada di rumah itu, maka suaminya akan mati juga karena menyentuhnya. Karena itulah Yurie segera melarikan diri. Hal ini dipengaruhi oleh ninjoo, yang dimiliki Yurie, karena dia menganggap suaminya adalah bagian dari lingkup uchi nya. Sementara ketika dia menghisap nyawa tetangganya, hal itu dia rasa perlu untuk mengembalikan kekuatan tubuhnya, dan agar dia bisa bertahan hidup. Hal ini sesuai dengan teori Ninjoo sangat mengedepankan 'kyookan' yang berarti perasaan simpati atau kehangatan yang dicurahkan oleh para anggota kelompok uchi untuk sesama anggotanya (Makino, 1996: 23-24). Yurie mendahulukan suaminya karena dia merasa suaminya sudah banyak menanamkan budi padanya, jadi dia layak membalasnya dengan perasaan simpati.

Sedangkan pada Kazami, walaupun dokter itu sudah merawatnya selama ini, dan pada awalnya Yurie menganggapnya sebagai orang yang ada dalam lingkar uchi-nya, wanita itu tidak memperdulikannya dan malah menghisap nyawanya. Hal ini terjadi karena Yurie merasa tidak wajib memberikan ninjoo pada dokter yang telah membuatnya merasa tidak nyaman ditangkap seperti binatang (Akagawa, 2010: 266-270). Yurie juga tetap menjaga kesetiaan pada suaminya. Para lelaki hidung belang yang dia ajak ke hotel, tidak pernah menyentuhnya. Dia yang selalu terlebih dahulu menghisap nyawa para lelaki itu, untuk melanjutkan hidupnya. Pada saat ini dia juga memberikan ninjoo pada suaminya dengan menjadi seorang istri yang tetap setia, dengan omoiyari dan shinsetsusa untuk suami yang ada dalam lingkar uchi nya (Akagawa, 2010: 140-142).

Di saat terakhir Koozoo lah yang memberikan ninjoo nya kepada istrinya, dengan mengatakan bahwa dia akan ikut mati bersama istrinya, karena dia tahu Yurie orangnya mudah merasa kesepian, dan sensitif, sehingga tidak bisa menuju dunia kematian sendirian (Akagawa, 2010: 310-313). Koozoo selama ini tidak merasakan ketidakpuasan hidup bersama istrinya. Dia sangat mencintai istrinya, dan sejak tahu penyakit Yurie dia berharap akan mati bersamanya, sebagai bukti cintanya pada wanita yang telah dinikahinya itu. 


\section{Utopia dalam Novel 午前 0 時の忘れ物 ‘ Gozen reiji no wasuremono' yang Mengandung Unsur Uchi-Soto}

Cerita ini berkisah tentang orang-orang yang menerima pesan dari kerabat terdekat mereka yang tewas karena kecelakaan bis. Setelah diangkat dari dalam danau tempat bis tersebut kehilangan kendali dan meluncur ke dasarnya, ada beberapa jasad yang belum juga ditemukan. Mereka itulah Orang-orang yang menghubungi kaum kerabatnya yang masih hidup untuk berkumpul di terminal bis Minorigaoka pukul 12 malam. Adapun orang yang menerima pesan itu ada seorang murid SMA, bos mafia Jepang, Yakuza yang ditemani para pengikutnya, seorang istri pengusaha kaya, yang datang bersama sekretaris suaminya, seorang atlit sprinter, seorang karyawan kantor, serta dua orang gadis yang sebetulnya tidak ada hubungannya dengan peristiwa itu, tetapi kebetulan saat itu mereka harus menginap di statsiun karena kehabisan uang untuk menggunakan hotel. Ketika bis maut itu tiba, terjadilah berbagai konflik, diantaranya peristiwa rencana pembunuhan bos yakuza oleh klan lawan.

Unsur Utopia yang dimunculkan di sini adalah, pesan dari orang-orang yang sudah tiada. Garis imajiner jelas ditorehkan untuk menandai satu bagian fiktif dari realitas. Orang-orang yang dihubungi para arwah yang tubuhnya belum ditemukan di dasar danau itu adalah orang-orang biasa yang hidup di masyarakat Jepang dalam kesehariannya. Seorang istri pengusaha, seorang anak SMA, seorang atlit, seorang karyawan perusahaan, bahkan seorang kepala bos yakuza. Dunia tempat kejadian ini adalah dunia masyarakat Jepang yang ril, namun kejadian yang digambarkan adalah fiktif. Hal ini sesuai dengan teori utopia dari Napier (dalam Purnama Sari, 2008) yang mengatakan bahwa, demi pelariannya terhadap realita, utopia Jepang umumnya memiliki logika terbalik dan tak jarang memutarbalikkan realitas.

Para arwah yang datang pada pukul 12 malam ke terminal bis Minorigaoka adalah para arwah yang jasadnya belum ditemukan, dan masih tetap terbenam di dalam danau tempat mereka menemui kecelakaan. (Akagawa, 1997: 18) Fenomena seperti ini erat kaitannya dengan Shinto, yaitu kepercayaan Jepang lama, yang menitikberatkan pada pemujaan arwah. Jasad yang sudah ditemukan pada kecelakaan itu, sudah disembahyangkan oleh kaum keluarganya, sementara mereka belum. Penyembahyangan untuk jasad biasanya dilakukan di kuil dengan upacara Shinosai, yang mengantarkan jazad kepada para kami (dewa) (Sadazumi, 2007). Sementara upacara pengusiran roh jahat yang mengganggu manusia disebut Oharai, biasanya upacara ini dilakukan pada saat adanya pembangunan gedung baru. Oharai dilakukan untuk meminta ijin para arwah penunggu tempat itu agar tidak menganggu proses pembangunan.

Akagawa memadukan antara kepercayaan bahwa tubuh jasad yang tidak diupacarakan belum dapat naik ke satu tempat yang penuh kedamaian. Dan dalam hal ini pertemuan dengan para kerabat merupakan obat bagi para arwah itu untuk dapat naik ke tempat yang lebih tinggi, mendekati para kami. Selain unsur arwah, Akagawa juga memadukan ceritanya dengan unsur Kriminal. Bos mafia Jepang, seorang yakuza tua bernama Kanazawa, datang ke tempat itu untuk bertemu dengan arwah istri dan cucunya. Kanazawa yang merasa sudah tua, memutuskan untuk ikut istri dan cucunya naik ke bis maut tersebut, membawanya ke dunia lain yang belum diketahuinya. Satu hal yang bertentangan dengan alam realita yang mendukung unsur utopia hadir di novel ini. 


\section{Tabel 4 Utopia dalam 午前 0 時の忘れ物 'Gozen reiji no wasuremono' yang Mengandung Unsur “Uchi” dan”Soto”, Ninjo dalam Masyarakat Jepang}

\begin{tabular}{|c|c|}
\hline Halaman bagian cerita & Utopia yang mengandung unsur Uchi-soto 'Ninjoo' \\
\hline $12-13$ & $\begin{array}{l}\text { Almarhum Jun yang merasa sangat dicintai Megumi, dan belum mengucapkan pesan } \\
\text { terakhir saat dia meninggal pada gadis itu mengirim pesan pada kekasihnya agar } \\
\text { menemui dia di terminal bis Minorigaoka, malam itu pukul } 12 \text { malam. }\end{array}$ \\
\hline $18-19$ & $\begin{array}{l}\text { Nagao seorang karyawan kantor mendapatkan pesan dari anaknya yang telah } \\
\text { meninggal dalam kecelakaan bis untuk menemui dia dan ibunya di terminal bis } \\
\text { Minorigaoka pukul } 12 \text { malam itu. }\end{array}$ \\
\hline 25 & $\begin{array}{l}\text { Sayuri Ueda, seorang atlit marathon menerima pesan dari Jun'ichi, pemuda yang } \\
\text { dicintainya yang meninggal dalam kecelakaan bis, untuk menemuinya di terminal bis } \\
\text { Minorigaoka pukul } 12 \text { malam itu }\end{array}$ \\
\hline $30-31$ & $\begin{array}{l}\text { Kanazawa seorang bos mafia Jepang yang sudah tua menerima pesan dari istri dan } \\
\text { cucunya yang telah meninggal dalam kecelakaan bis, untuk menemui mereka di } \\
\text { terminal bis Minorigaoka pukul } 12 \text { malam itu. }\end{array}$ \\
\hline $40-43$ & $\begin{array}{l}\text { Mitsuko Morimoto, seorang istri dari direktur perusahaan terkemuka, Kaoru } \\
\text { Morimoto, mendapat pesan dari almarhum suaminya yang tewas dalam kecelakaan bis } \\
\text { untuk menemuinya di terminal bis Minorigaoka pada pukul } 12 \text { malam itu. }\end{array}$ \\
\hline $248-251$ & $\begin{array}{l}\text { Mitsugu Ooki melindungi Kanazawa dengan seluruh hati karena merasa bosnya ada di } \\
\text { kelompok lingkar uchi-nya. Padahal dia mempunyai niat untuk berkhianat dan } \\
\text { menyebrang ke klan lawan, dengan membantu mereka untuk membunuh bosnya. } \\
\text { Akan tetapi ketika bosnya akan ditembak, Mitsugi justru memasang badannya agar } \\
\text { peluru yang ditembakkan tidak mengenai orang tua itu. }\end{array}$ \\
\hline 206-208, 253 & $\begin{array}{l}\text { Jun memaksa Megumi untuk sama-sama mati dengannya. Jun merasa karena dia } \\
\text { adalah kekasih Megumi, maka gadis yang ada dalam lingkar uchi-nya wajib } \\
\text { memberikan ninjoo kepadanya berupa tindakan ikut mati bersamanya. Bahkan untuk } \\
\text { itu dia meminta seorang Yakuza untuk mencelakai Megumi, agar dia mati dan bisa } \\
\text { ikut dengannya. }\end{array}$ \\
\hline $275-282$ & Jun menyadari bahwa justru dialah yang harus memberikan ninjoo nya pada Megumi \\
\hline
\end{tabular}

(Akagawa, 1997)

Unsur uchi dan soto, ninjoo dalam novel ini terdapat pada keinginan para arwah, untuk menyampaikan pesan terakhir kepada kaum kerabatnya. Hal ini termasuk ninjoo, karena mereka merasa berhutang budi pada orang di lingkar uchi-nya namun belum sempat mengatakan apa-apa. Sementara Megumi merasa belum menyatakan bahwa dia tidak akan pernah melupakan Jun, sampai kapanpun. Nagao sangat ingin pergi bersama istrinya Atsuko dan anaknya Tooru, namun karena kesibukan pekerjaannya dia tidak sempat untuk ikut pergi bersama keluarganya menumpang bis maut tersebut. Dan itu membuatnya sangat tersiksa, dia ingin menyampaikan rasa penyesalannya pada keluarganya tersebut. Dan ini termasuk ninjoo, karena dia merasa telah berhutang budi pada istrinya selama ini (Akagawa, 1997: 18).

Mitsugu Ooki telah sepakat dengan klan lawan untuk membantu membunuh bosnya, Kanazawa. Akan tetpi karena selama ini Kanazawa-lah yang telah mendidiknya dan menjadikanya sebagai yakuza andal, dia malah melindungi Kanazawa ketika pesuruh klan lawan hampir membunuhnya dengan tembakan. Hal ini sesuai dengan teori ninjoo sangat mengedepankan 'kyookan' yang berarti perasaan simpati atau kehangatan yang dicurahkan oleh para anggota kelompok uchi untuk sesama anggotanya (Makino, 1996: 23-24). Demikian juga dengan Kanazawa yang mengatakan bahwa dia tidak punya siapapun di dunia ini selain istri dan cucunya. Karena itu dia memutuskan untuk ikut ke dalam bis itu, untuk mati. Tindakan ini didasari oleh ninjoo, yang termasuk di dalamnya omoiyari, yaitu suatu tindakan untuk menyenangkan hati seseorang. 
Jun awalnya menginginkan kekasihnya Megumi ikut mati bersamanya, dia kesepian dan tidak mau sendirian di dasar danau yang dingin dan sepi itu. Jun pun sampai menyuruh salah seorang dari yakuza klan lawan yang sedang menanti kesempatan baik untuk membunuh Kanazawa, agar mencelakai Yumi (Akagawa, 1997: 253). Akan tetapi akhirnya pemuda tersebut menyadari bahwa karena Megumi ada di lingkar uchi-nya dia yang harus memberikan ninjoo pada gadis itu,berupa omoiyari, melakukan satu kebaikan untuk orang yang dicintainya, dengan membiarkan dia hidup. Kata omoiyari menurut kamus gakushuu kokugojiten (Kaneda, 1993: 134) berarti 人を考えてやる気持ち、 同情 'hito wo kangaete yaru kimochi', 'doujyou', perasaan untuk melakukan sesuatu bagi orang lain, atau merasa punya perasaan yang sama dengan orang lain.Akhirnya Jun memutuskan untuk hanya membawa pulang perasaan gadis itu padanya, itu yang membuat dia merasa bahagia karena tidak akan pernah dilupakan Megumi (Akagawa, 1997: 275-282). Akan tetapi justru gadis itu merasa dia sama sekali tidak mengerti perasaan Jun, yang mengajaknya untuk mati bersama. Megumi merasa tidak membalas kebaikan yang selama ini Jun berkan padanya, dia memaksa untuk ikut masuk ke dalam bis maut tersebut (Akagawa, 1997: 281-282), walaupun akhirnya berhasil dihentikan oleh Jun.

\section{SIMPULAN}

Setelah menganalis ketiga novel di atas penulis mengambil kesimpulan untuk unsur utopia berdasarkan tabel di bawah ini :

Tabel 5 Kesimpulan Unsur Utopia dalam Inti Cerita Tiga Novel Jepang Kontemporer karya Jiro Akagawa dalam hubungannya dengan unsur uchi-soto ' ninjoo' pada asyarakat Jepang

\begin{tabular}{|c|c|c|}
\hline Judul Novel & Gambaran Utopia inti dari cerita & Kategori Utopia \\
\hline \multirow[t]{2}{*}{ Odayakana Rinjin } & $\begin{array}{l}\text { Mahluk halus dapat hidup layaknya } \\
\text { manusia }\end{array}$ & $\begin{array}{l}\text { 1. Kontras dengan realita dan logika terbalik } \\
\text { 2. Satire }\end{array}$ \\
\hline & $\begin{array}{l}\text { Ninjoo : Terlalu mempunyai perasaan } \\
\text { omoiyari sehingga mengundang bahaya } \\
\text { bagi keluarga }\end{array}$ & \\
\hline \multirow[t]{3}{*}{ Shi ga futari wo wakatsu made } & Penyakit aneh menjangkiti Yurie & \\
\hline & $\begin{array}{l}\text { Yonehara, yang hanya bisa hidup dengan } \\
\text { menghisap nyawa orang lain }\end{array}$ & Kontras dengan realita dan logika terbalik \\
\hline & $\begin{array}{l}\text { Ninjoo: Perasaan cinta yang ada pada } \\
\text { suami dan istri, membuat suami rela mati } \\
\text { bersama istrinya yang mempunyai } \\
\text { penyakit aneh }\end{array}$ & \\
\hline Gozen reiji no wasuremono & $\begin{array}{l}\text { Arwah yang jasadnya belum ditemukan } \\
\text { dapat mengirim pesan pada kerabatnya } \\
\text { yang masih hidup, dan bisa bertemu } \\
\text { mereka kembali untuk terakhir kalinya. } \\
\text { Ninjoo : keinginan yang kuat dari para } \\
\text { arwah mampu menggerakkan energi, dan } \\
\text { membuat mereka bisa menemui kerabat } \\
\text { mereka untuk terakhir kalinya. }\end{array}$ & Kontras dengan realita dan logika terbalik \\
\hline
\end{tabular}

(Akagawa, 2006; Akagawa, 2010; Akagawa, 1997)

Dalam cerita bergenre fantasi ternyata lebih mudah menemukan unsur kebalikan realistik yang merupakan unsur inti dari utopia. 


\section{DAFTAR PUSTAKA}

Akagawa, J. (2006). おだやかな隣人 (Tetangga yang menyenangkan). Japan: 徳間書店.

Akagawa, J. (2010). 死が二人を分つまで(Sampai mati memisahkan keduanya). Japan: 集英社

Akagawa, J. (1997). 午前0 時の忘れもの(Barang yang tertinggal pada jam 12 malam). Japan: 集英 社

Asmowiyoto, W. (2007) Nilai Tukar Rupiah Takluk oleh Yen. 14 November 2007 Bandung: Harian Pikiran Rakyat.

Hirabayashi, Y. dan Hama, M. (1992). Gaikokujin no tame no nihongo reibun-mondai shiriizu 10 keigo.Tokyo: Aratake Shuppan.

Kaneda, I.( 1996).Gakushuu no tameno kokugojiten.Tokyo: Shogakukan.

Makino, S. (1996). Uchi to Soto no Gengo Bungaku-Bunpo wo Bunka de Kiru. Tokyo: ALC

Nurgiyantoro, B. (1998). Teori Pengkajian Fiksi. Yogyakarta: Gadjah Mada University Press

Oono, Shin. (1978). Nihongo no Bunpou wo Kangaeru. Tokyo: Iwanami Shoten.

Purnama Sari, Lediah (2008). Analisis konsep utopia dalam Novel Kappa karya Akutagawa Ryuunosuke. Skripsi. Jakarta : Universitas Bina Nusantara.

Sadazumi, Motegi (2007). Shinsoosai. Kokugakuin University. 24 Feb 2007. Diunduh dari http://eos.kokugakuin.ac.jp/modules/xwords/entry.php?entryID=1054

Wan Seng, A. (2007). Rahasia Bisnis Orang Jepang: Langkah Raksasa Sang Nippon Menguasai Dunia. Jakarta: Hikmah 